\title{
Caciquismo y sistema político durante la Restauración en Andalucía Occidental: estado de la cuestión y líneas de investigación.
}

\author{
ANTONIO BARRAGAN MORIANA
}

Hace ya algunos meses en una ponencia presentada a los $\mathbf{V}$ Coloquios de Historia de Andalucía que se desarrollaron en Córdoba en mayo de 1.990, el profesor L. Alvarez Rey al referirse al estado de la cuestión de la historia política de la Andalucía contemporánea, insistía en la necesidad de revisión de los contenidos de la mayor parte de los manuales y obras generales al uso, referentes al análisis de nuestros siglos XIX y XX, debido fundamentalmente no tanto a la utilización de determinados criterios metodológicos o enfoques teóricos, 'como al importante volúmen de publicaciones, estudios, líneas de investigación abiertas en los últimos años que, de forma irremediable decía, han contribuido a ampliar el conocimiento de los diferentes procesos políticos, sociales, económicos o culturales de nuestrá región, a cuestionar no pocos planteamientos basados en la traspolación mecanicista de determinadas conclusiones poco o escasamente ajustadas a la realidad, a la matización o rectificación de algunas interpretaciones tenidas como definitivas, en suma, a poner de manifiesto la necesidad, si no de reescribir en 'su totalidad la historia contemporánea de Andalucía, sí a tener en cuenta este nuevo bagaje de información, de conocimientos que los últimos años nos han venido aportando. Desde aquellos momentos de mayo de 1.990 nuevas publicaciones, avances en determinados proyectos de investigación, incluso la culminación total o parcial de algunos trabajos, así como el desarrollo de diferentes seminarios, jornadas, encuentros o reuniones científicas no hacen sino corroborar lo que señalo; de ello es buena muestra la exposición que sobre el proyecto «Política y políticos en Andalucia occidental durante la Restauración" ha realizado esta mañana el profesor Sánchez Mantero, y sobre todo el contenido de las comunicaciones que se van a desarrollar en este congreso sobre caciquismo y II República en nuestra región. Y en efecto, con relación al material que me ha correspondido analizar relativo al ámbito de la Andalucía occidental 
durante la Restauración, el grueso fundamental de los trabajos se refieren al estudio de los procesos electorales, y en segundo término, al del caciquismo siendo pocos los que tienen como objeto de estudio cuestiones institucionales, ideológicas o económicas, lo cual nos hace ver que, pese a la escasa validez de los procesos electorales como dimensión exclusiva de la vida política, estos siguen siendo utilizados como elemento importante en el análisis de las estructuras caciquiles; en este sentido se nos presentan estudios sobre la coyuntura electoral de 1891 (municipales,generales, senatoriales), y sobre otros momentos importantes en la evolución de la Restauración (1.881, 1.899, 1.918 y 1923), sobre determinados distritos o ciudades (Valverde,Montilla, Jerez, Cádiz, Osuna, El Viso del Alcor, Sevilla,etc.) sin que falten, finalmente, planteamientos minetodológicos como puedan ser los referidos a la sociología electoral comparada o de normativa electoral.El segundo bloque temático es el referente al caciquismo y su expresión en una serie de distritos/ciudades o instituciones planteándose una serie de cuestiones novedosas como puedan ser los mecanismos de control de las élites políticas sobre determinadas instituciones, el papel caciquil de las empresas mineras y mercantiles, el impacto de la crisis económica o de la conflictividad sobre las estructuras caciquiles etc.

Sin que sea este el lugar para extendernos sobre la cada vez mas evidente recuperación de la historia política, en lo que probablemente insistirán estos días voces mas autorizadas que la mía, ni mucho menos sobre las razones que lo han motivado para el conjunto de los estudios de nuestros siglos XIX y XX, sí dejar constancia de que, por fortuna, nos hallamos lejos de aquella práctica historiográfica tan combatida en su momento, entre otras corrientes, por los"Annales" o por el materialismo histórico, lejos de esa historia netamente positivista que situaba en el ámbito de lo político todos los elementos explicativos del proceso histórico; por el contrario, nos encontramos con una forma de ver las cosas que, aún conservando su tradicional apego a lo narrativo y cronológico, en esta "nueva Historia política" es notoria su renovación teórica y metodológica, su mas completa y abierta gama de líneas de trabajo, un mayor rigor documental y de fuentes, la integración como dimensiones básicas de análisis de otros elementos sociales y económicos que actúan sobre los procesos políticos, en fin, su conexión con otras ciencias o campos metodológicos ( política,sociología, economía, estadística, etc.); en definitiva, se trata de una nueva definición de su estatuto científico, de una clara resituación en el conjunto de los estudios sociales.

Con relación a la historia política de la Restauración en las provincias de Andalucía occidental, hemos de señalar, desde el principio, la constatación de la influencia favorable de estos innegables avances teóricos y metodológicos sobre el conocimiento de la Historia contemporánea 
de la región; ello no quiere decir, corno veremos, que no quede un importante camino por desbrozar, un conjunto de problemas necesitados de un mejor conocimiento, probablemente una serie de interpretaciones sobre determinadas cuestiones políticas que deban ser alteradas,cuestionadas o, en su caso, matizadas, etc. Vamos a intentar,en estas líneas que siguen, plantear cual es el "estado de la cuestión al respecto, cuales son las vías de investigación aún abiertas, cuales los ámbitos de análisis que atraen la atención de los estudiosos, qué fundamentales aportaciones se han desarrollado recientemente, así como sacar a la luz una serie de reflexiones que, sin pretensión de concluir nada,contribuyan modestamente a dar una imagen lo mas completa posible de este panorama al que nos referimos.

Hemos procedido metodológicamente en primer lugar desarrollando un conjunto de ideas sobre los diversos campos de estudio, diríamos clásicos, de nuestra historia política contemporánea, intentando resaltar las aportaciones y los vacíos mas visibles existentes, para, a continuación, insistir en las líneas de investigación mas novedosas que se vienen desarrollando, terminando con un apéndice informativo en el que pretendemos incluir todos aquellos trabajos en curso o finalizados ( bibliografía, artículos, tesis,ponencias y comunicaciones a congresos, líneas de investigación, etc.) de los que hemos tenido conocimiento.Por supuesto que se trata de intentar configurar una especie de arcbivo abierto al que, en el futuro, puedan ir incorporándose las sucesivas aportaciones fruto de la investigación en los diferentes ámbitos de la historia política de nuestra región, en la confianza de que sirva como elemento de trabajo y única manera que, a nuestro juicio,pudiera acercarnos a un conocimiento real de las claves políticas de nuestra historia contemporánea.

$\mathrm{Y}$ en efecto, como señalábamos mas arriba, a pesar de las innegables aportaciones a la historia política producidas durante los años ochenta, son todavía muy amplios los campos de análisis que quedan por abordar, algunos de ellos absolutamente básicos, y esto por cuanto que, desde la propia investigación sobre temas como elecciones, sistema de partidos, grupos de presión, funcionamiento de las diversas instituciones, etc. basta la incorporación de nuevas pautas teóricas o metodológicas sobre las cuestiones como el caciquismo, la estructura del poder en sus diferentes niveles, relaciones entre poder político y económico, entre conflictividad social y sistema político etc., por poner una serie de ejemplos significativos, son cuestiones parcial o insuficientemente abordadas, a nuestro juicio, y que sólo la lenta y contínua aportación de monografías de carácter provincial o comarcal,nos están ayudando a tener un conocimiento de la auténtica realidad de la historia política de Andalucía. Sírvanos de ejemplo de lo que señalamos con anterioridad que, cor. 
referencia a las 4 provincias de Andalucía occidental que consideramos en nuestro trabajo, no tenemos ni siquiera un censo biográfico de diputados y senadores, mucho menos de autoridades locales y provinciales (alcaldes y diputados), auténtica élite política, para el período 1876/1923; si exceptuamos la provincia de Sevilla estudiada por el profesor Sánchez Mantero ${ }^{1}$, así como por la aportación parcial de Puech Suances sobre los inicios de la Restauración en esa misma provincia ${ }^{2}$, o el reciente trabajo de Rodríguez Gaytan de Ayala $^{3}$ sobre la de Cádiz que, aunque no se refiere al conjunto del período restauracionista, supone una importante ampliación de nuestros conocimientos en este aspecto o, finalmente, las aportaciones generales de Millán Chivite para el conjunto de la región, de las de Córdoba y Huelva no poseemos, que nosotros sepamos, mas que una información muy fragmentaria, trabajos en curso, sobre diversas etapas o políticos restauracionistas, precisamente sobre una cuestión que, como señalábamos mas arriba,podríamos considerar básica en el conocimiento de la historia política del período.En relación con lo anteriormente expuesto y aludiendo a la revitalización de un género habitualmente denostado, el biográfico, señalar la reciente y valiosa incorporación de trabajos como los de Ortiz Villalba sobre el republicano cordobés Vaquero Cantillos, los de Herrera Mesa sobre el también republicano posibilista Herrera Zamorano ${ }^{6}$, el de Ayala Pérez sobre Romero Robledo ${ }^{7}$, los de $\mathrm{M}$. Jaramillo y M.J. Moreno Hinestrosa sobre Burgos y $\mathrm{Mazo}^{8}$, o finalmente , el de M.D. Gómez López sobre el dirigente conservador cordobés Conde de Torres Cabrera ${ }^{9}$,entre otros, dimensión ésta a la que, pensamos, sin

(1) SANCHEZ MANTERO, $R$. La Restauración en Andalucia occidental: Estado de la cuestión.Ponencia presentada al Seminario Influencia electoral y movilización política en la España de la Restauración 1.875/1.923. Fundación Ortega y Gasset. Gijón 1.986.

(2) PUECH SANCHEZ, K. Política y políticos sevillanos en los inicios de la Restauración 1.874/1.881. Tesis de Licenciatura inédita. Sevilla 1.980.

(3) RODRIGUEZ GAYTAN DE AYALA, A. Elecciones y élites parlamentarias en Cadiz 1.903/ 1.923.Rev.Espacio tiempo y Forma, serie V, 3.1 UNED 1.990. Madrd.

(4) MILLAN CHIVTEE, J.L. Andaluces y Andalucia bace cien años. (Aproximación a un estudio generacional andaluz durante la restauración 1.875/1.898. Rev. Gades $n^{2} 3$. Cádiz 1.979.

(5) ORTIZ VILLALBA, J.Apéndice biográfico a la reedición de la obra de E. Vaquero, -Del drama de Andalucia. Recuerdos de luchas rurales y ciudadanas.Córdoba 1.987.

(6) HERRERA MESA, P.P. Aportaciones a la biografía de un republicano cordobés: D. Pablo Herrera Zamorano. Tesis de Licenciatura inédita. Córdoba 1.983.

(7) AYALA PEREZ, J.A. .Un político de la Restauración: Romero Robledo. Antequera 1.974

(8) JARAMILLO, M. Estudio biográfico de M. Burgos y Mazou.Tesis de Licenciatura inédita UNED 1.988.MORENO HENESTROSA, M.J. Moguer en la época de la Restauración, lugar de nacimiento de D. Manuel Burgos y Mazon.Congreso sobre Caciquismo y República en Andalucía. El Puerto de Santa María, sep. de 1.991.

(9) GOMEZ LOPEZ, Ma.D. El Conde de Torres Cabrera, un vástago tardío de la Ilustración.Tesis de Licenciatura inédita. Córdoba 1.986. 
duda alentará tanto la utilización de documentación procedente de archivos privados, como la reciente aparición de determinadas monografías, como son las de los profesores Alvarez Junco;Santos Juliá o Tusell/Calvo sobre Lerroux, Azaña y Giménez Fernández respectivamente ${ }^{10}$.

Desde otro punto de vista, y en la medida en que cada vez se hace mas necesaria la incorporación de la documentación proveniente de archivos privados para el conocimiento de la historia de la Restauración, hemos de hacer constar que son aún muy escasos los estudios que tienen en cuenta este tipo de fuentes documentales, aunque, y ello hay que reconocerlo, contamos ya con importantes aportaciones, y seguramente el caso de M.S. Alonso citado por el profesor Sánchez Mantero para el estudio de las conexiones de la familia Ybarra con el P. Conservador, los de M:D. Gómez López sobre el archivo del dirigente conservador cordobés Conde de Torres Cabrera, sean algunos de los mas significativos, trabajos en los que la utilización de este tipo de información, a la vez que se manifiesta insustituible, amplía las perspectivas de análisis de aspectos fundamentales del período o, incluso, termina revisando o completando anteriores interpretaciones.

Son dos los aspectos centrales sobre los que hemos articulado en este trabajo las publicaciones, documentación líneas de investigación, etc. y a los que vamos a dar un tratamiento específico desde el punto de vista metodológico:caciquismo y sistema político.

Con respecto al primero de ellos podemos señalar que si hay un elemento caracterizador del período restauracionista, este no es otro que el caciquismo, auténtica dimensión sintetizadora de la realidad política entre 1.874/1.923; ni que decir tiene que a pesar de las indudables connotaciones que tradicionalmente ha planteado relativas a su función básica de corrupción electoral, es evidente que el fenómeno caciquil en la España de la Restauración era algo mucho mas amplio que el simple falseamiento de los procesos electorales con su corolario de coacciones, fraudes etc. y que, consiguientemente, abarcaba otras pautas (económicas, sociales, culturales, institucionales e incluso personales) de la vida diaria; sobre él han existido básicamente dos corrientes o interpretaciones en absoluto contrapuestas, sino, a nuestro modo de ver complementarias: a) la defendida por quienes piensan (Varela Ortega, Romero Maura, Tusell Gómez) que se trata de una forma de dominación política én la que sobresale el absoluto control de la Administración, base de la desmovilización y docilidad del electorado y, b) los que, desde otro punto

(10) ALVAREZ JUNCO, J. El emperador del paralelo. Lerroux y la demagogia populista .Madrid 1.990. SANTOS JULLA, Manuel Azaña.Una biografía polütica Madrid 1.990.TUSELL, J. y CALVO, J. Gimémez Fernández, precursor de la democracia cristiana. Sevilla 1.990. 
de vista, acentúan los determinantes económicos (Tuñón de Lara, Herr, Temime, Chastagnaret) para explicar los fundamentos de la dominación caciquil; con referencia a Andalucía, hace algunos años el profesor A.M.Calero, mostraba las carencias que la interpretación del fenómeno del caciquismo tenía con relación al conjunto de la región, y ello aún a pesar de que desde años atrás circulaba entre los estudiosos del tema la tan citada obra de Tusell.Para Calero la razón fundamental de esa insuficiencia de análisis no era otra que las limitaciones teóricas con que este, en general, se abordaba, en la medida en que, concluye,que el problema del caciquismo no es tanto una cuestión de coacción política, sino de desmovilización y que, y cito textualmente, «...lo que nos permitirá entender la realidad política andaluza de la Restauración no es la reiterada contemplación, entre indignada y divertida de los mil y un pucherazos y demás babilidades caciquiles, sino la investigación rigurosa y profunda de la naturaleza, causas y modalidades de la desmovilización popular; $y$ consiguientemente, lo que nos permitirá entender la crisis de la Restauración es la naturaleza y formas de la movilización que a lo largo de ella se produjo, y que tiene su expresión mas clara y final en el uso pacífico de los cauces legales que los andaluces bicieron en las elecciones municipales de Abril de 1931...."11.

El caciquismo en Andalucía, por consiguiente, en su dimensión básica de desmovilización política ha sido objeto de análisis por una serie de estudiosos que ya tendremos ocasión de citar en el apartado de este trabajo referido à los procesos electorales, pero además podemos observar como esta vertiente de estudio mas amplia sobre el citado fenómeno sociopolítico por la que se viene abogando, tiene cumplida cuenta en nuestra comunidad a tenor de algunos de los últimos trabajos sobre el particular, algunos de los cuales están siendo desarrollados estos días; tales son las pretensiones de quienes se esfuerzan por estudiar aspectos como la vinculación caciquismo/violencia, politica/conflictividad social (Barragán Moriana, Cepillo Galvín, o los trabajos de Arcas Cubero y Ramos Palomo para la provincia de Málaga), sus relaciones con determinados grupos de presión económicos o empresariales (compañías mineras, industriales, comerciales o sociedades agrarias), como han puesto de manifiesto Florencio Puntas y Encarnación Lemus para Sevilla, Peña Guerrero para Huelva que analiza el papel "caciquil. de la Cia. minera de Riotinto en el distrito de Valverde y Barragán Moriana para Córdoba que asimismo estudia el papel de otra cia. extranjera la S.M.M.P., o sociales $e$

(11) CALERO AMOR, A.M. LLa crisis sacial andaluza en el primer tercio del siglo XX: partidos políticos y movimiento obrero. Ponencia al I Congreso de Andalucismo Histórico.Actas.Sevi'lla, Fundación Blas Infante 1.985. 
institucionales (Mateo Avilés caciquismo/clero, López Calvo caciquismo e instituciones locales, etc.), las necesidades de control de la Administración local y provincial (Navarro Domínguez,Ramírez Olid, Ponce Alberca para la provincia de Sevilla, Montañés Primicia para el campo de Jerez que introduce además aspectos relativos a la incidencia de la crisis agraria finisecular y las dificultades de la modernización agraria y sus repercusiones en el entramado político, López Calvo y Casas Sánchez que han estudiado los conflictos caciquiles en los pueblos del distrito de Priego de Córdoba, feudo de D.Niceto Alcalá Zamora), sus vinculaciones con el poder judicial (Cruz Artacho, Jiménez Martínez, M.S. Alonso), en la medida en que este se manifestaba como instrumento clave en allanar las dificultades para el control de la administración pública, la facilidad de su asentamiento y pervivencia en función del escaso grado de instrucción (Fernández Portillo,Santander Díaz, etc.), el papel de la prensa como defensora o crítica de las potentes estructuras caciquiles (Braojos Garrido, Pérez Serrano, Polonio Armada, Casas Sánchez ), las relaciones entre el aparato y la propaganda eclesiästica y el caciquismo (Domínguez León), para incluso, finalmente, tener conocimiento de la existencia de algunas líneas de investigación novedosas desde el punto de vista metodológico: la referente a las raices y movilidad ruptura de las estructuras caciquiles de los periodos anterior (monarquía isabelina/sexenio) y posterior (Dictadura de Primo de Rivera/II República ) a la Restauración, como plantean, entre otros Gutiérrez Molina, Piñeiro Blanca para la provincia de Cádiz, López Calvo y Casas Sánchez para el distrito de Priego de Córdoba o Alvarez Rey y Ponce Alberca para Sevilla, o,desde otra perspectiva la utilización de la bistoria oral (Díaz Aznarte) como fuente fundamental para su investigación.En definitiva, y con ello enlazamos con las consideraciones de Calero que referenciabamos al inicio de este apartado, de lo que se trata fundamentalmente no es sino de explicarnos, de dar respuesta al por qué las clases no hegemónicas aceptaron durante tanto tiempo un sistema político que se había creado precisamente para dominarlas, por qué utilizaron tan escasamente los mecanismos electorales, a partir de 1.890 el sufragio universal, para acabar con él organizándose adecuadamente y llevando al poder a sus representantes (*).

Con relación al sistema político procederemos atendiendo a nuestro grado de conocimiento de los partidos y a la cuestión electoral, aunque previamente a ello debamos puntualizar un par de cuestiones que, aún siendo obvias, no importa reiterar:la primera no es otra que el escaso valor, salvo en muy contadas excepciones, de los procesos electorales debido a su consabido y sistemático falseamiento,a la puesta en marcha de los mecanismos caciquiles, como exclusivo procedimiento de análisis de la lucha política y, en segundo lugar, con referencia al sistema de 
partidos, como suficientemente han señalado Varela Ortega, Linz, Tusell, ${ }^{12}$ entre otros, se trató de agrupaciones con escaso poder de movilización, con respecto de los partidos monárquicos auténticas "tertulias caciquiles" $y$, con respecto a los grupos de la oposición republicana y socialista, instancias que manifiestan progresivamente su incapacidad para convertirse en alternativas, en su conjunto, un sistema impotente para integrar a la mayor parte de los sectores sociales e institucionales.

Con referencia a los partidos monárquicos, esas tertulias caciquiles, "amigos políticos", como fueron bautizados por Varela Ortega, la necesidad de conocer su estructura a nivel provincial, su funcionamiento y relaciones entre ellos y con la oposición, vinculaciones con el poder económico agrario, financiero o industrial, su forma de concebir y desarrollar el clientelismo político, su posición y actitudes en momentos clave de la Restauración, en definitiva, su estrategia en lograr la consabida desmovilización y control de las instituciones durante la etapa restauracionista su conocimiento es algo que, a pesar de lo mucho y valioso que en su momento aportara el profesor Tusell para el conjunto de la región, se amplía por momentos gracias a importantes y novedosos trabajos, a investigaciones de carácter provincial.Como ha sido recientemente señalado,el estudio de la izquierda política, en general, resultaba mas atractivo para los analistas e historiadores, quedando, con frecuencia, el de los movimientos/partidos de la derecha y que en la Restauración tradicionalmente la historiografía encasillaba como los "partidos del turno" relegado a simpatizantes o, desde otro de punto de vista, a críticos que, con perspectivas claramente reduccionistas, tendían, bien a desarrollar determinados planteamientos laudatorios, bien a homogeneizar un objeto de estudio que contenía niveles ciertamente diferenciados. Pensamos que trabajos como los de M. Sierra Alonso sobre la familia Ybarra y el conservadurismo sevillano, el de Molina Lamothe sobre la crisis del 98 y el nacimiento de la Unión Nacional en Sevilla, los de Peña Guerrero/Lara Ródenas sobre Burgos y Mazo y el conservadurismo onubense, o los de Acosta Ramírez y Barragán sobre la clase política senatorial y sobre las vinculaciones del poder político y el control de la tierra para la provincia de Córdoba son líneas de investigación que indudablemente contribuyen a ámpliar el conocimiento de un sector político importante y a romper determinados clichés interpretativos que contribuirán a revisar no pocos aspectos históricos del período; no obstante ello, señalar que posiblemente sea aquí en donde, a nuestro juicio,

(12) VARELA ORTEGA, $J$. Los amigos políticos.Partidos elecciones y caciquismo en la Restauración 1.875-1.900.Madrid 1.977.TUSELL GOMEZ, $J$. Oligarquía y caciquismo en Andalucia 1.890-1.923. Barcelona 1.976.LINZ, J.J. .El sistema de partidos en Españan.Madrid 1.976. 
quede una importante parcela de investigación por realizar y en dónde esa utilización de archivos y documentación privados, volvemos a insistir en ello, complemente el conocimiento que, básicamente a través de fuentes hemerográficas, tenemos de los partidos del turno en nuestra región.Ciertamente también aquí la aparición de obras como las de Avilés/ Tusell y González Hernández ambas sobre el maurismo ${ }^{13}$, las de Colin $\mathrm{M}$. Winston ${ }^{14}$ sobre relaciones entre la derecha política y el movimiento obrero, la de A. Bachoud ${ }^{15}$ sobre partidos políticos y el conflicto de Marruecos, entre otras, sirvan para estimular los análisis y a ampliar las perspectivas.

De los partidos de oposición antimonárquica, ni siquiera del Partido Socialista juzgado por J.J. Linz como el único que puéde catalogarse como tal, y cuyo desarrollo y consolidación se juzga decisivo en la marcha política de la Restauración, poseemos un conocimiento suficiente para el conjunto de la región, lo que, como denunciara en su momento, A.M. Calero $^{16}$, ha facilitado la presencia de no pocos tópicos en el estudio del movimiento obrero andaluz.En este sentido, como ha señalado el profesor Macarro Vera ${ }^{17}$, la historia del socialismo, del partido socialista en Andalucía durante la Restauración no puede ser abordada como la concreción de un proyecto político regional, del desarrollo de unas pautas y directrices únicas y homogéneas, sino que, por el contrario, dada la falta de vertebración política en el conjunto del período, tal historia hay que juzgarla desde la variedad, entrando en el análisis de prácticas políticas y sindicales que, frecuentemente, ofrecen aspectos bien dispares desde el punto de vista provincial y relativos a temas como el mayor/menor nivel de desmovilización política, el diferente grado de conflictividad social en algunos períodos y coyunturas, nivel de implantación de las organizaciones anarquistas de la F.T.R.E. o de la C.N.T., la trayectoria política y organizativa de los diferentes sectores republicanos, etc. De esta forma, el nivel de información que poseemos sobre los primeros pasos del socialismo en Andalucía es muy precario limitándose a una serie de referencias difícilmente contrastadas; con relación a las provincias objeto de nuestro análisis, conocemos insuficientemente temas como el origen y grado de implantación de

(13) AVILES FARRE, J. y TUSELL GOMEZ, J. La derecha española contemporänea.Sus origenes: el maurismo-Madrid 1986.GONZALEZ HERNANDEZ, M.J. .Ciudadania $y$ acción.Madrid 1.990.

(14) COLIN, M. WINSTON .La clase trabajadora y la derecha en Españan.Madrid 1.989.

(15) BACHOUD, A. Los españoles ante las campañas de Mamuecos. Madrid 1.988.

(16) CALERO AMOR, A.M. Movimientos saciales en Andalucía 1.820/1.936.Madrid 1.976, pag. 23 y ss.

(17) MACARRO VERA, J.M. .El socialismo en Andalucía 1.900/1.936. en .El socialismo en las nacionalidades y regiones. Anales de Historia de la Fundación Pablo Iglesias, $n^{2} 3$. Madrid 1.988, pags.105 y ss. 
los primeros núcleos socialistas, su relación con el anarquismo o el republicanismo, su praxis politica y borizontes ideológicos, la posición del partido en los diferentes procesos electorales, su presencia en las instituciones locales, etc. imposibilitándose, de esta manera, el cuestionamiento de lo que planteado para la provincia de Córdoba por Díaz del Moral, fuera elevado por muchos como análisis interpretativo para el conjunto de la región andaluza «...la bistoria del socialismo en Córdoba, como en el resto de Andalucia, puesta en parangón con la del anarquismo, encierra interesantes enseñanzas para los bombres que aspiran a dirigir las muchedumbres y a ser escultores de pueblos.Frente a las grandes conmociones libertarias, el movimiento obrero socialista ha sido tan debil que ninca rizó la más leve ola de los mares burgueses de la provincia, y salvo algün que otro gobernador miedoso, nadie estaba enterado de que existía.... ${ }^{18}$.Por fortuna, está próxima a su defensa la tesis doctoral del profesor García Parody que, hasta el momento, viene adelantando algunos resultados de su investigación y que, no dudamos, contribuirá a dar la auténtica imagen del socialismo, aún en la provincia de Córdoba, hasta la época de la I Guerra europea (*). Por el contrario, conocemos mejor,gracias a los trabajos de Macarro Vera, Calero Amor y al mío propio las andaduras del socialismo andaluz en los momentos finales de la Restauración tanto en lo concerniente a su nivel de organización, a su acción política, electoral y sindical, así como, finalmente, a sus presupuestos ideológicos en una etapa decisiva en la maduración del movimiento obrero en España (").

Con respecto del republicanismo, que duda cabe que el horizonte de su conocimiento se amplia día a día y que cada vez son mas los trabajos que se unen a esas investigaciones que, aunque recientes, resultaron auténticamente pioneras y referidas a dos provincias de la Andalucía oriental (Málaga y Almería) y que constituyeron las tesis de los profesores Arcas Cubero y Martínez López respectivamente ${ }^{19}$. Ciertamente, y aunque no disponemos de estudios semejantes desde el punto de vista provincial,para el ámbito geográfico de la Andalucía occidental, son cada vez mas numerosas las aportaciones que se vienen ocupando de poner de manifiesto algunos de los aspectos históricos fundamentales del republicanismo, tales como su nivel de implantación, sus presupuestos ideológicos, su acción política y electoral, su sempiterno fraccionalismo, sus relaciones con los otros grupos de la oposición antimonárquica (regio-

(18). DIAZ DEL MORAL, J. «Historia de las agitaciones campesinas andaluzas.Madrid 1.977, pag. 140

(19) ARCAS CUBERO, F. "El republicanismo malagueño durante la Restauración 1.875/ 1.923..Córdoba 1.985.MARTINEZ LOPEZ, F. El sistema politico de la Restauración: partidos elecciones y caciquismo en Almeria 1.875/1.89a.(T.D.I). 
nalistas o socialistas), en definitiva, sacar a flote, analizar, todo el conjunto de dificultades que imposibilitaron que el republicanismo no se convirtiera en alternativa a la monarquía hasta abril de 1.931.En este sentido, los trabajos de López Estudillo, Barragán Moriana, Herrera Mesa y Peña Guerrero/Lara Ródenas sobre las provincias de Sevilla, Córdoba y Huelva respectivamente amplían ese nivel de nuestros conocimientos y aunque no agotan, ni mucho menos el campo de análisis del republicanismo en la Andalucía occidental durante la Restauración, sí contribuyen a deshacer esa imagen tópica de un republicanismo débil, desideologizado, sin calado ni apoyos sociales y con una presencia prácticamente testimonial en la sociedad política andaluza, pero insistimos, en nuestra opinión, aún esta por realizar ese estudio sobre el republicanismo en sus diversas fracciones (posibilistas,progresistas, centralistas y federales), en los momentos de auge de la "unión republicana", en sus relaciones con los otros sectores de la oposición antimonárquica (socialistas y regionalistas), su acción política y electoral, sus relaciones con el movimiento obrero etc. que, como señalara en su momento A.M. Calero, nos ayude a explicar el por que ese intento democratizador que en su conjunto fue el republicanismo, ese esfuerzo de adecuación de los programas, métodos y estrategias del republicanismo a las demandas de una serie de sectores y capas sociales, también en Andalucía estuviera acompañado por tan escaso éxito.

Una de las dimensiones políticas de la Restauración que en el ámbito andaluz mereció la atención de una forma, incluso diríamos desmesurada, por parte de estudiosos e investigadores fue la concerniente al movimiento regionalista; decimos atención desmesurada en la medida en que, a nuestro juicio, es ingente la gran cantidad de artículos, trabajos, bibliografía, etc. de muy diverso valor y contenidos científicos ${ }^{20}$ en relación con la importancia política que en Andalucía tuvo este fenómeno durante la Restauración, con su discreta capacidad de proyección popular que, en todo caso, no lograría una cierta entidad hasta la coyuntura de la II República.Desde los trabajos pioneros de Lacomba Abellán, Ruiz Lagos, Acosta Sánchez, Aumente Baena, Moreno Navarro, etc., entre otros, y a través fundamentalmente de los encuentros habidos sobre*andalucismo histórico*, cinco hasta la fecha, han sido numerosos los estudios que se han ocupado de analizar tanto la personalidad de sus dirigentes, el contenido teórico de su obra, la praxis politica ciel andalucismo, sus conexiones con las movilizaciones populares y la

(20) LACOMBA ABELLAN, J.A. .Regionalismo y autonomía en la Andalucia contemporánea (1835/1936). Granada 1.988, recoge la mas completa bibliografía general y específica sobre los diferentes aspectos del andalucismo histórico. 
conflictividad social, su reiterada denuncia del sistema y del caciquismo, sin que falte quienes, de manera un tanto oportunista, hayan aprovechado la ocasión para fabricar recetas acerca de su idoneidad como alternativa política.Desde luego a toda esta eclosión de publicaciones, bastantes de las cuales muy cuestionables científicamente, sobre el andalucismo histórico no fue ajena la coyuntura creada en los años iniciales de la democracia en los que la recuperación de las señas de identidad andaluzas fue un elemento de primer orden en los programas de los partidos y movimientos sociopolíticos.Sin que neguemos la validez de las aportaciones de una serie de estudiosos, entre los que destacaríamos, al margen de los de carácter general que señalábamos al principio y refiriendonos a nuestro ámbito de la Andalucía occidental, los de los profesores Braojos, Cortines, Parias Sainz de Rozas, Villar Movellán, etc. que para la provincia de Sevilla han trabajado sobre temas como la prensa, cuestión agraria o el mundo de la arquitectura regionalista, los estudios de Millán Chivite y Pérez Serrano sobre las raíces sociales o la crítica regionalista al caciquismo en la de Cádiz, así como, finalmente, los trabajos de López Calvo y Calvo Poyato que para la provincia de Córdoba han establecido la posición del regionalismo andalucista en determinados aspectos electorales, políticos y conflictuales (*), pensamos que la funcionalidad de los nuevos congresos que se convoquen en nombre del "andalucismo histórico" deberían ir encaminados, sin mas, a ser un lugar de encuentro de estudiosos de la historia social, política, cultural y económica de Andalucía, sin que fuera necesario que se realzase un objeto de análisis, a nuestro juicio, claramente agotado.

Otro de los ámbitos básicos de la historia política y en el que ésta se da la mano con la sociología es el del análisis de los procesos electorales. Durante la Restauración, aún partiendo de la base, como señalábamos mas arriba, del falseamiento total de la práctica electoral, del auténtico secuestro de la voluntad popular, de la evidente desmovilización política, es seguro que su análisis nos pone en mejores condiciones de conocer los entresijos del caciquismo.Mucho se ha hablado de la deuda que esta rama de la ciencia política, la sociología electoral, tiene contraida con las obras de Martínez Cuadrado y Varela Ortega y, desde luego para Andalucía, con la de Javier Tusell ${ }^{21}$ y en efecto, con relación a la época restauracionista y en el ámbito de la Andalucía occidental, ampliamos continuamente nuestro conocimiento de como se desarrollaron los procesos electc:-rles, cual fue el comportamiento político de nuestra región

(21) MARTINEZ CUADRADO, M. Elecciones y partidos politicos en España.2 vols. Madrid 1.969. VARELA ORTEGA, J. LOS amigos politicos........, ob. cit. y TUSELL GOMEZ, $J$. . Oligarquía y caciquismó....... ob. cit. en nota 12 de este trabajo. 
hasta la implantación del sufragio universal, etapa no recogida en su obra por Tusell, cuáles las dimensiones mas sobresalientes de la práctica caciquil, de que manera se configuró la desmovilización política de la región, en definitiva, cómo las élites dirigentes consiguieron imponer,aún a duras penas, ese simulacro de estabilidad constitucional característico del período.Y en este sentido,no cabe duda que los trabajos de Alvarez Rey, Navarro Domínguez, González Fernández y Ramírez Olid para Sevilla, los de Lara Ródenas y Peña Guerrero para Huelva, los de Gloria Espigado, Marchena Domínguez, Montañés Primicia y Rodríguez Gaytán para Cádiz y, finalmente, los de López Calvo y Barragán Moriana sobre Córdoba nos amplían el panorama de nuestros conocimientos en temas como el análisis de determinadas coyunturas significativas (las' de 1.881 en el primer turno liberal en Cádiz, las elecciones generales de 1.918, de 1.919, de 1.923 en Sevilla, Córdoba y Huelva, las de 1.891 tras la implantación del sufragio universal, el estudio relativo a las elecciones generales de 1.899 en Andalucía de J.A. Jiménez López que nos introduce en el clima político de la región tras el desastre del 98, etc.), el análisis de los procesos electorales municipales con la incorporación de los mecanismos de control institucional, el conocimiento de la dinámica política de determinados distritos o comarcas ( Los Alcores; Osuna, Jerez, Priego de Córdoba, Valverde, Montilla, etc.), sin que falten en esta línea de investigación aspectos ciertamente novedosos, como señalábamos mas arriba, tales como el análisis de sociología electoral comparada, precisamente sobre la aplicación del sufragio universal en dos etapas diferentes políticamente de nuestra historia contemporánea, el papel *caciquil» jugado en los procesos electorales por determinadas instancias económicas o empresariales, la relación existente entre nivel de conflictividad, desmovilización electoral y desarticulación política, o, finalmente, el debate existente en torno a determinadas cuestiones, como normativa electoral,papel doctrinal de la iglesia, caciquismo, etc. $\left(^{*}\right)$

No obstante lo cual, con ser mucho el camino recorrido en el ámbito de la sociología electoral, aún quedan aspectos importantes, líneas de investigación apenas iniciadas que, por fortuna, merecen la atención de jóvenes estudiosos; señalemos algunas: a) el análisis de los procesos electorales para el Senado que ha sido, hasta el presente, algo escasamente y mal estudiado, ni siquiera abordado deforma precisa por los clásicos de la sociología electoral, lo que sin duda ha motivado la circulación de no pocos tópicos sobre los comicios y la clase política senatorial; como señala uno de sus estudiosos, Acosta Ramírez, (*) que en la actualidad realiza una tesis doctoral sobre el senado durante la Restauración, en este campo, tal es nuestro grado de desconocimiento, que debemos empezar por las preguntas mas sencillas: ¿ quienes fueron los senadores de la restauración?, ¿ 
cual era su filiación política ?, ¿ que grado de endogamia se practicó en la clase senatorial,$\dot{i}$ que vinculaciones tuvieron con determinadas instituciones económicas o culturales ?, si existió algún nivel de patrimonialización del cargo, si fue, como parece, el último eslabón de la carrera política o si, por el contrario, existieron *senadores natos*, si hubo diferencias políticas, económicas o institucionales entre el "curriculum" de diputados y senadores, etc.Estas y muchas otras son algunas de las cuestiones cuya respuesta, pensamos, puede ayudar a completar el conocimiento de la historia de la Restauración en Andalucía, b) otro de los ámbitos de análisis es el de los procesos electorales administrativos, tanto los relativos alas municipales, como a las Diputaciones provinciales, así como el conocimiento de la gestión de las diferentes instituciones (ayuntamientos, diputaciones provinciales fundamentalmente), ya que es en este nivel en donde se articulan los fundamentos mas notorios del sistema caciquil; ello es lo que apuntan algunos de los trabajos locales presentados en este u otros coloquios como los de Navarro Domínguez, Ponce Alberca y Ramírez Olid, para la provincia de Sevilla, los de Peña Guerrero, Lara Ródenas y Moreno Hinestrosa para la de Huelva, Montañés Primicia y Rodríguez Gaytán para Cádiz y López Calvo, Casas Sánchez y Barragán Moriana para la de Córdoba (*), y c) el estudio pormenorizado de los diferentes distritos en lo que se refiere a la realidad de las fuerzas politicas en presencia, tanto las del turno como las de la oposición, a sus estrategias electorales, a su capacidad real de desmovilización y critica del sistema, en suma, a todo aquello que determina los auténticos entresijos del funcionamiento del sistema caciquil. $Y$ ello, aún a pesar del indudable mérito que en su día supuso la aportación de la obra de J. Tusell para el conjunto de la región que, no obstante, debe ser completada en el período 1.876-1.890, etapa del sufragio censitario, y aumentada, en la medida de lo posible para el resto del período.En este sentido cobran una especial relevancia análisis de procesos electorales de determinadas coyunturas, como los presentadas sobre la aplicación del sufragio universal, los de 1.899 para el conjunto de la región en plena resaca de la crisis política finisecular, y ya en pleno siglo XX los relativos a las comicios de 1.918 o de 1.919 , en la coyuntura de descomposición del sistema y, por último, a las elecciones de 1.923, que nos dan idea del grado de obsolencia política al que había llegado la "vieja política*.

No queremos finalizar nuestra intervención sin hacer mención a la existencia de una serie de trabajos que podíamos denominar «estudios de coyuntura que obviamente tienen por objeto el estudio de determinados momentos claves en la evolución histórica del período restauracionista, en circunstancias en las que se produce una auténtica inflexión en el conjunto del entramado sociopolítico. Tal es el sentido de trabajos como los de Molina Lamothe relativo a las repercusiones de la crisis del 98 en 
Sevilla, el de Ponce Alberca sobre la configuración y gestión política de la Diputación sevillana en los momentos de transición entre la Restauración y la Dictadura, el de Lacomba Abellán para la crisis de 1.917 en la provincia de Córdoba o, finalmente, los de M. Peña Guerrero asimismo en la coyuntura del advenimiento de la dictadura de Primo de Rivera en la provincia de Huelva (*).

En definitiva, y con ello terminamos, pensamos que un encuentro de la naturaleza del que aquí nos convoca estos días va a incidir de manera positiva en el esclarecimiento de algunos de los problemas políticos de un período fundamental en nuestra historia contemporánea (1.890/ 1.936) en la medida en que es balance; pero que duda cabe de que, al mismo tiempo al recoger las lineas de investigación más novedosas, las reflexiones y aportaciones fruto del posible debate, nos pondrá en condiciones de dar un salto adelante, de aproximarnos al conocimiento de las claves reales de la historia contemporánea de Andalucía.

\section{BIBLIOGRAFIA. CACIQUISMO DURANTE LA RESTAURACION EN ANDALUCÍA OCCIDENTAL}

Acosta Ramírez, Fco. :Las elecciones senatoriales de 1.891 en Andalucía. I Congreso sobre caciquismo y república en Andalucía. El Pto. de Sta. María, sep. 1.991

Arcas Cubero, F. -Republicanismo y regionalismo durante la Restauración: los intentos de creación de un partido republicano andaluz. en Actas del I Congreso de Andalucismo Histórico. Sevilla/Antequera 1.983

Cálero Amor, A.M. $\mathrm{El}$ andalucismo político en la crisis de la Restauración. en Actas del II Congreso de Andalucismo histórico. Sevilla 1.987

Calero Amor, A.M. .La crisis social andaluza del primer tercio del XX: partidos políticos y movimiento obrero. Actas I Congreso de Andalucismo Histórico. Sevilla 1.985

Cepillo Galvín, M.A. .La violencia popular como resultado del alto grado de frustración producido ante unos procesos y resultados electorales insatisfactorios. I Cong. sobre caciquismo y república en Andalucía.El Pto. de Santa María, sep. de 1.991

Díaz Aznarte, J.J. El caciquismo en la memoria. Un estudio a partir de las fuentes orales. I Congreso sobre caciquismo y República en Andalucía. El Pto. de Santa María, sep. de $1.991\left({ }^{*}\right.$ *) Enriquez del Arbol, E. *Republicanismo y masonería: Datos andaluces". I Congreso sobre caciquismo y república en Andalucía. El Pto. de Sta.María sep. 1.991 (* *) $^{*}$

Fernández Bastarreche, F. .El ejército en la Andalucía de Alfonso XII. II Congreso de Historia de Andalucía. Córdoba 1.991

Fernández Portillo de la Oliva, P. -Caciquismo y educación. I Congreso sobre caciquismo

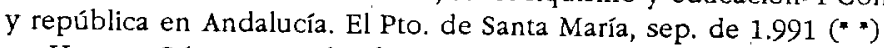

Herrera Gómez, M. .El sufragio universal en los orígenes de las sociedades del bienestar.

I Congreso sobre caciquismo y república en Andalucía El Pto. de Sta. María, sep. de 1:991

Jiménez López, J.A. .Programas y partidos políticos andaluces en las cortes de 1899.. I Congreso sobre caciquismo y república en Andalucía. El Pto. de Sta. María, sep. 1.991

La aparición del asterisco a lo largo del texto ( *) hace referencia a los diferentes trabajos (libros, artículos, comunicaciones a congresos, etc:) que, clasificados por provincias se reseñan en el apéndice bibliográfico. 
Mateo Avilés, E. .Caciquismo y clero en la Andalucía de la Restauración: entre el protagonismo y la crítica. en Actas del I Congreso de Andalucismo Histórico

Martín de la Guardia, R.Aproximación estadística a la prensa andaluza de la edad contemporánea. II Congreso de Historia de Andalucía. Córdoba 1.991

Millán Chivite, J.L. •Andaluces y Andalucía hace 100 años. Aproximación a un estudio generacional andaluz de la Restauración 1875/1.898. Rev. Gades 3. Cádiz 1.979

Ramos Rovi, M.J. .Normativa electoral de la ley de sufragio universal de 1.890.. I Congreso sobre Caciquismo y República en Andalucía. EL Puerto de Sta.María sep. 1.991

Rueda Hernán, G. LLa enseñanza primaria y media en la Andalucía de la Restauración .. II Congreso de Historia de Andalucía. Córdoba 1.991

Sánchez Mantero, R. .La Restauración en Andalucía occidental. Estado de la cuestión. Ponencia presentada al Seminario .Influencia electoral y movilización política en la España de la Restauración 1.875/1.923. Fundación Ortega y Gasset. Gijón 1.986

Santander Díaz, M. Caciquismo y educación. I Congreso sobre caciquismo y república en Andalucía. El Pto. de Santa María, sep. de $1.991\left({ }^{*}\right.$ *)

Tusell Gómez, J. Mligarquía y caciquismo en Andalucía 1890/1923. Barcelona 1.976 Tusell Gómez, J. •El sistema caciquil andaluz comparado con el de otras regiones españolas 1902/1923x. I Congreso de Historia de Andalucía. Córdoba 1.979

\section{Provincia: SEVIILA}

Alvarez Rey, L. .El Partido maurista en Sevilla (1.914/1.923). II Congreso de Historia de Andalucía. Córdoba 1.991

Alvarez Rey, L. Elites políticas en Sevilla durante la crisis de la Restauración (1898/1931). Bases sociales y control institucional Rev. Espacio, Tiempo y Forma ${ }^{2} 3$. UNED Madrid 1990

Andrés Gallego, J. :La Iglesia de Sevilla y la polêmica sobre la acción política de los católicos españoles 1900/1906. Rev. Archivo Hispalense 171/73. Sevilla 1.973

Braojos Garrido, A. .El regionalismo autonomista andaluz en la prensa sevillana (1900/ 1936)).Notas sobre un proyecto de investigación. en *Nacionalismo y regionalismo en España. Córdoba 1.985

Braojos Garrido, A. José Laguillo.Memorias. Veintisiete años en la dirección de El Liberal de Sevilla (1907/1.936). Sevilla 1.979

Domínguez León, J. .Iglesia y política en Andalucía a fịnales del siglo XIX. El adoctrinamiento a través de la prensa católica sevillana. I Congreso sobre caciquismo y república en Andalucía. El Pto. de Sta. María, sep. de 1.991

Florencio Puntas, A. -La respuesta de la patronal sevillana al problema de las subsistencias, 1.914/1.923. II Congreso de Historia de Andalucía. Córdoba 1.991

González Fernández, A. .Enseñanza primaria e institución popular en Sevilla 1894/1903.

II Congreso de Historia de Andalucía. Córdoba 1.991

González Fernández, A. LLas elecciones de 1.918, elecciones de la renovación en Sevilla. I Congreso sobre caciquismo y república en Andalucía. El Pto. de Sta. María, sep. 1.991

Lemus, E. r.a Cámara de Comercio de Sevilla. Entidad empresarial y proyección política.

I Congreso sobre caciquismo y política en Andalucía. El Pto. de Sta. María, sep. 1.991

León Alonso, R. .Un texto republicano/minorista en la Sevilla de comienzos del siglo XX: el semanario El Combate. II Congreso de Historia de Andalucía. Córdoba 1.991

López Estudillo, A. Federalismo y obrerismo en Sevilla (1.881/1.883). II Congreso de Historia de Andalucía. Córdoba 1.991

Molina Lamothe,J.M. .La crisis del 98 en Sevilla: del cierre de tiendas al nacimiento de la Unión Nacional 1898/1900). Actas del I.C.H.A. Andalucía Contemporânea. Córdoba 1.979

Navarro Domínguez, J.M. .Caciquismo y control municipal en la comarca de Los Alcores.

I Con. sobre caciquismo y República en Andalucía. El Pto. de Sta. María sep. de 1.991

Navarro Domínguez, J.M. .El Circulo conservador de El Viso del Alcor. II Congreso de Hist. de Andalucía. Córdoba 1.991 
Ponce Alberca J. .La Diputación provincial de Sevilla y el advenimiento de la Dictadura de Primo de Rivera. I Cong. sobre caciquismo y república en Andalucía. El Pto. de Sta. María sep. de 1.991

Puech Suances, K. «Política y políticos sevilianos en los inicios de la Restauración 1874/ 1881. T.L.I. Universidad de Sevilla 1.980

Ramírez Olid, J.M. Sociedad y caciquismo en Osuna durante el reinado de Alfonso XIII. I Congreso sobre Caciquismo y Rep. en Andalucía. El Pto. de Santa María sep. de 1.991

Ramírez Olid, J.M. .Las elecciones en el distrito de Marchena durante la Restauración. II Congreso de Historia de Andalucía. Córdoba 1.991

Rodríguez Bernal, E. 'La Exposición Iberoamericana de 1.929. El Ayuntamiento'y los partidos políticos sevillanos ante el inicio del certámen 1909/1914•, en Actas de las VI jornadas Andalucía y América. Sevilla 1.987

Ruiz Sánchez, J.L. •Política e Iglesia sevillana durante la Restauración. Los orígenes de la Liga Católica. T.L.I. Univ. de Sevilla 1.988

Ruiz Sánchez, J.L. .Magisterio de la Iglesia y poder político en la Sevilla de la Restauración. I Congreso sobre caciquismo y república en Andalucía. El Pto. de Sta. María, sep. de 1.991

Ruiz Sánchez, J.L. -Los católicos sevillanos ante el reinado de Alfonso XIII: entre la tradición y el progreso. Rev. Esp. Tiempo y Forma, n 3 UNED. Madrid 1.990

Sánchez Mantero, R. -Los diputados sevillanos durante la Restauración. Rev. Archivo Hispalense 220, Sevilla 1.989

Sierra Alonso, M. Empresarios y políticos en la Sevilla de la Restauración: la familia Ybarra. T.L.I. Univ. de Sevilla 1.989

Sierra Alonso, M. EEl partido conservador en la Sevilla de la Restauración: la familia Ybarra.. Rev. Esp. Tiempo y forma, $n^{\circ} 3$ UNED. Madrid 1.990

Sierra Alonso, M. ‘lientes, amigos y elecciones. Mecanismos de control electoral en la Sevilla de la Restauración. I Congreso sobre caciquismo y república en Andalucía. El Puerto de Sta. María, sep. de 1.991

\section{Provincia: HUELVA}

Ferrero Blanco, Liaño. 1886/ M.D. .Sociedades mercantiles en Huelva:y Miró 1936. II Congreso de Hist. de Andalucía.Córdoba 1991

Lara Rodenas, J.C. .Política y lucha de partidos en la Huelva de la Restauración: Las elecciones a Cortes de 1.919. Rev. Esp. Tiempo y Forma $n^{2} 3$ UNED. Madrid 1.990

Moreno Hinestrosa, M.J. - Moguer en la época de la Restauración: lugar de nacimiento de un política importante (D. Manuel Burgos y Mazo). I Congreso sobre caciquismo y república en Andalucía. El Pto. de Sta. María, sep. 1.991

Peña Guerrero, M.A. El funcionamiento interno de los partidos políticos durante la Restauración: Huelva 1898/1923. II Congreso de Hist. de Andalucía. Córdoba 1.991

Peña Guerrero, M.A., Lara Rodenas J.C. y Domínguez, "La crisis de 1.917 en Huelva.. en -Huelva en su historia. 3. Huelva 1.990

Peña Guerrero M.A. -La élite política de Huelva ante la contienda electoral de 1.923.. Rev. Esp. Tiempo y Forma $n^{2} 3$ UNED.Madrid

Peña Guerrero, M.A. .Caciquismo y poder empresarial. El papel político de las compañías mineras en la provincia de Huelva. I Congreso sobre Caciquismo y República en Andalucía. El Puerto de Sta. María, septiembre de 1.991.

\section{Provincia: CADIZ}

Correa López, M.J. Anarquismo nietzscheano en Cádiz: El Anticristo. I Congreso sobre caciquismo y república en Andalucía. El Puerto de Sta. María, sep. 1.991 
Espigado Tocino, G. .Un estudio de sociología electoral comparada: el sufragio universal en Cádiz 1.873 y 1.891. I Congreso sobre caciquismo y república en Andalucía. El Pto. de Santa María, sep. de 1.991

Marchena Domínguez, J. Las elecciones en el Cádiz de 1.881: el comienzo del turno liberal.

I Congreso sobre Caciquismo y República en Andalucía. El Pto. de Sta. María, sep. 1.991

Millán Chivite J.L. -Raíces sociológicas del andalucismo histórico en Cádiz (1.900/1.936n). Actas del III Congreso de Andalucismo Histórico. Sevilla 1988

Montañés Primicia, E. .Economía agrícola y representación política. Jerez de la Frontera 1.891-1.923. I Congreso sobre caciquismo y república en Andalucía. El Pto. de Sta. María, sep. de 1.991

Pérez Serrano, J. sLa crítica regionalista al sistema caciquil en Cádiz durante la época de la Restauración. I Congreso sobre caciquismo y república en Andalucía. El Pto. de Sta. María, sep. de 1.991

Rodríguez Gaytán de Ayala, A. Elecciones y élites parlamentarias en Cádiz 1903/1.923*. Rev. Esp. Tiempo y Forma.

\section{Provincia: CORDOBA}

Acosta Ramirez, Fco. .Cordobeses en el senado de Alfonso XII..II Congreso de Hist. de Andalucía. Córdoba 1.991

Barragán Moriana, A. .Conflictividad social y desarticulación política en la provincia de Córdoba.1918-1920. Córdoba 1.990.

Barragán Moriana, A. LLuchas políticas en el trienio bolchevique en la provincia de Córdoba: las elecciones generales de 1.919. Actas del III Coloquio de Hist. de Andalucía.Córdoba 1.985

Barragán Moriana, A. LLas fuerzas políticas en Córdoba en la crisis de la Restauración (1.917/1.923). Actas del Seminario sobre Eloy Vaquero.Córdoba 1.990

Barragán Moriana, A. sufragio Universal y elecciones municipales: Córdoba mayo de 1.891..I Congreso sobre caciquismo y II República en Andalucía.El Pto. de Santa $\mathbf{M}^{\mathbf{z}} 1.991$

Barragán Moriana, A. -La actividad politica de los andalucistas en el ayuntamientode Córdoba durante el .trienio bolchevique. Actas del I Congreso de andalucismo histórico. Sevilla 1.985

Barragán Moriana, A. .Caciquismo y sufragio universal: Las elecciones generales de 1.891 en la provincia de Córdoba..II Congreso de Historia de Andalucía.Córdoba 1.991

Calvo Poyato, C. -Regionalismo andaluz y conflictividad campesina. Córdoba 1.917/ 1.920. T.L.I. Universidad de Córdoba 1.983

Camero Ramos, J. .Cabra en su prensa 1.880/1.910. Córdoba 1.988

Casas Sánchez, J.L. .El enfrentamiento entre valverdistas y nicetistas en Priego (Córdoba), pueblo natal de Alcalá Zamora. I Congreso sobre Caciquiasmo y II República en Andalucía.

El Pto. de Sta: María 1.991

García Parody, M. EEl origen del socialismo en Lucena. Encuentros de Historia Local.La Subbética.Córdoba 1.990

Garcia Parody, M. "Sociedades obreras de Puente Genil a comienzos del siglo XX.II Encuentros de Historia Local.La Campiña.Córdoba 1.990

Garcia Parody, M. sociedades obreras del alto Guadalquivir hasta la crisis de 1.917•. III Encuentros de Historia Local. Córdoba 1.991

Herrera Mesa, P.P. .Los republicanos cordobeses durante el primer periodo liberal en la Restauración 1881/84. Anuario de Historia Contemporánea. Granada 1.984

Herrera Mesa, P.P. El partido posibilista cordobés en las elecciones generales de 1.881. Actas del III Coloquio de Historia Contemporánea. Córdoba 1.983

Herrera Mesa, P.P. AAportaciones a la biografía de un republicano cordobés: P.P. Herrera Zamorano 1.845/1.914.T.T.L. Universidad de Córdoba 1.984 
Lopez Calvo, M. •Cacquismo y resignación popular: Priego de Córdoba 1.868/1.923. Córdoba UNED 1.988

Lopez Calvo, M. EEl regionalismo andaluz en Córdoba hasta la dictadura de Primo de Rivera 1.916/1.923. T.L.I. Córdoba 1.984

Lopez Calvo, M. -La coalición republicana/regionalista en las eleecciones municipales de 1.917 en Córdoba..Actas del II Congreso de andalucismo histórico.Sevilla 1.987

Moreno Gómez, Fco. sMovimiento obrero, caciquismo y represíon en Córdoba durante 1.919. AXERQUIA $n^{2} 12$. Córdoba 1.984

Ortiz Villalba, J. .El republicanismo andalucista en Córdoba. Actas del seminario sobre E. Vaquero. Córdoba 1.990

Polonio Armada, M.J. :La prensa local en Montilla durante el reinado de Alfonso XIII. II Congreso de Historia de Amdalucía. Córdoba 1.991

Polonio Armada, M.J. -Las elecciones generales de 1.903, 1.905 y 1.907 en el distrito de Montilla..I Congreso sobre Caciquismo y II República en Andalucía.El Pto. de Santa María 1.991

Romero Atala, T. -La Cámara de Comercio de Córdoba durante la etapa de C.Carbonell como presidente de la misma 1.899/1.917.II Congreso de Historia de Andalucía. Córdoba 1.991

Sarmiento Martín, E. .La industria cordobesa durante el periodo 1900/1936. II Congreso de Historia de Andalucía.Córdoba 1.991

Sarmiento Martin, E. .La S.E.C.E.M. Estudio de una empresa industrial. T.L.I. Universidad de Córdoba 1.989

Sevilla Guzmán, E y Lopez Calvo, M. .Para una tipología del andalucismo histórico en Córdoba. Actas del Seminario sobre Eloy Vaquero. Córdoba 1.990 